\title{
Sex Estimation in Brazilian Sample: Qualitative or Quantitative Methodology?
}

Viviane Ulbricht ${ }^{1}$, Cristiane Martins Schmidt ${ }^{2}$,
Francisco Carlos Groppo ${ }^{3}$, Eduardo Daruge Júnior ${ }^{4}$,
Dagmar de Paula Queluz ${ }^{5}$, Luiz Francesquini Júnior ${ }^{4 *}$

Aim: This study carried out cranial measurements (in $\mathrm{mm}$ ) [Zygion-Zygion (Zy-Zy);Zygion-Glabella-right side(Zy-Ga-right); Zygion-Glabella-left side (Zy-Ga-left); Zygion-Glabella-mean (Zy-Ga-mean); Rhinion-Anterior Nasal Spine (Rhi-ANS); Nasal Width (Na Wid); Nasion-Anterior Nasal Spine (Na-ANS); Glabella-Anterior Nasal Spine (Ga-ANS); Glabella-Prosthion (Ga-Pr)], to verify whether they are dimorphic. Methods: We used skulls from the Eduardo Daruge Laboratory of Forensic Physical Anthropometry, which did not present growth abnormalities and belonged to the age range of 18 to 100 years. Linear measurements were performed by digital caliper, properly calibrated. Inter and intra-calibrator calibration was performed by obtaining as result the value of 0.98 (considered excellent). Results: We found that all measures carried out are dimorphic, and we were able to create a logistic regression model (logit: Sex $=-33.6+(0.15 \times$ Zy-Zy $)+$ $(0.21 \times$ Rhi-ANS $)+(0.16 \times$ Na-ANS $))$ to estimation the sex Conclusions: We concluded that the developed quantitative method results in $85.2 \%$ sensitivity, $76.2 \%$ specificity, and $81.1 \%$ accuracy, being, therefore, more effective in the prediction of sex than the mere random hit.

Keywords: Forensic Dentistry. Forensic Anthropology. Sex Characteristics. Skull.
Received: May 11, 2017

Accepted: August 10, 2017

\section{Corresponding author: Luiz Francesquini Júnior Faculdade de Odontologia de Piracicaba - UNICAMP Departamento de Odontologia Social Avenida Limeira, 901 - CEP: 13.414-903 Piracicaba, SP, Brasil \\ E-mail: francesq@unicamp.br Phone: +55 19 98304-6173 cial Dentistry, Piracicaba $\mathrm{SP}, \mathrm{Br}$}

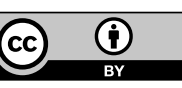




\section{Introduction}

The identification process has forensic physical anthropometry as its tool, which, although not permitting to establish the identity of a corpse (bones), allows to determine sex ${ }^{1}$ and ancestry and estimate age and height ${ }^{2}$. Although the international literature recommends that ancestry must be established before sex, in Brazil, such rule has been modified, due to the large number of miscegenation in the Brazilian population growth ${ }^{2}$

Based in the publications review of the last fifteen years ${ }^{3}$ on the methods of anthropometric identification used by various authors, researchers have found a distribution in six categories: visual examination of bones; anthropometric measurements of bones; anthropometric measurements with subsequent statistical analysis in the form of discriminant function analysis; time and sequence of teeth eruption; radiographic examination of the internal structure of bones; and microscopic examination of the inner structure of the bone.

Reviewing the situations that created the need for performing bone anthropometry, from 1971 to 1981 , authors ${ }^{4}$ have verified that the bones most found in disaster situations and/or mass accidents were the skull, femur, and jaw.

In situations with large number of bones, such as: explosions, wars, other mass disasters, and aviation accidents, the sex determination (separation into male and female) allows a considerable time gain in the process of identity establishment ${ }^{1}$, which is important in the daily activities of an Institute of Medicine, Legal Dentistry, and Forensic Physical Anthropometry.

Sex estimation is a primary component for identifying skeletonized individuals in Forensic Physical Anthropology ${ }^{5}$. It can be qualitative and/or quantitative (using logistic regression mathematical formulas), and both must be done judiciously, considering the ethnic or regional group of the sample, the time period in which it was held, among other situations.

For the qualitative method, a study ${ }^{6}$ evaluated the conduct of several authors and stated that the bizygomatic width, mastoid length, zygomatic process width, and mastoid height, in that order, are the most important features for sex determination.

Rogers ${ }^{7}$ (2005) studying 17 qualitative characteristics to determine sex, authors have concluded that the anterior nasal aperture, zygomatic extension, size and roughness of the maxilla and supraorbital ridge are the most dimorphic ones, followed by the mentum and nasal crest shapes and mastoid size.

Verifying the sex in known population groups by qualitative methodology is possible, provided that the Expert has prior knowledge of the population group to which this belongs ${ }^{8}$.

Currently, several authors ${ }^{9,10}$ have reported in their studies that the metric method (qualitative) cannot be replaced only by the visual method (qualitative), but, in practice, some mathematical models that were created by national sample do not faithfully reproduce the results found by its idealizers, which puts the expert in state of alert, because one can make mistakes in the application of such regression models ${ }^{2}$.

By the quantitative method, one can determine the sex in the skull by numerous structures and several linear measures, namely: 
- $\quad$ bicondylar width, mandibular angle, minimum ramus width ${ }^{11}$;

- $\quad$ bizygomatic width, ramus height, face depth"2;

However, the mandibular angle is not very useful for determining the sex of Africans from Pretoria ${ }^{13}$.

Because of the miscegenation that occurred per region in our population, we think that the mathematical models created should be properly validated in other samples of population groups by Brazilian geographic region, to verify the real hit and viability of using this technique in the Brazilian territory.

In the same research line, one should also look at cases in which the Deoxyribonucleic Acid (ADN) testing does not allow to establish the identity of a corpse. A study ${ }^{14}$ analyzed mandibles of pre-Hispanics from the Canary Islands using three identification methods, namely:

- visual inspection;

- osteometric measures;

- analysis of DNA amelogenin.

They obtained, respectively, $66.04 \%$ hit, followed by $72.2 \%$ and $73.78 \%$.

From this result, one can infer the need to associate methodologies, depending on the financial availability, to achieve greater security in the identification process.

\section{Material and methods}

This study is in accordance with the Brazilian Resolution no. 466/12 of the National Health Council, Ministry of Health, which regulates research involving human beings, and had prior approval of the Research Ethics Committee at the Piracicaba Dental School, University of Campinas (CAAE: 38522714.6.0000.5418).

This is a cross-sectional analytical observational study based on file of human bones of both sexes, with 136 from females and 184 from males, aged between 18 and 100 years, and races.

To start the measurements, we promoted inter and intra-examiner calibration. Linear measurements were performed (Zygion-Zygion; Zygion-Glabella-right side; Zygion-Glabella-left side; Zygion-Glabella (mean); Rhinion-Anterior Nasal Spine; Nasal Width; Nasion-Anterior Nasal Spine; Glabella-Anterior Nasal Spine; Glabella-Prosthion) in three different time periods in 25 bones, with an interval of a month between them.

The choice for linear measures used bone structures that are indicated in the literature ${ }^{10,15}$ as dimorphic. Ended this step and with tools duly calibrated, we measured the rest to reach 185 skulls of the Eduardo Daruge Laboratory of Forensic Physical Anthropology, with known sex, age, and race.

To carry out the measurements, we used a digital caliper (Stainless-Hardened ${ }^{\circledR}$ 150 mm, Mauá, São Paulo, Brazil)

Data were submitted to the Shapiro-Wilk and Levene's tests to assess, respectively, the distribution and equality of variances (homoscedasticity) of the variables under study. Student's t test and Chi-squared test also were conducted, as well as logistic regression (backward stepwise - Wald), Hosmer-Lemeshow and Nagelkerke tests. 


\section{Results}

The calibration result was considered excellent $(I C C \geq 0.75)$ for all calibrated measurements. Table 1 shows the means ( \pm standard error) of the variables studied according to the sexes and races.

Table 1. Means ( \pm standard error) of the variables studied according to the sex.

\begin{tabular}{|c|c|c|c|c|}
\hline & & Female $(n=84)$ & Male $(n=101)$ & p-value ${ }^{1}$ \\
\hline \multirow{3}{*}{ Race } & White & $47(56 \%)$ & $62(73.8 \%)$ & \multirow{3}{*}{0.51} \\
\hline & Black & $16(19 \%)$ & $13(15.5 \%)$ & \\
\hline & Brown & $21(25 \%)$ & $26(31 \%)$ & \\
\hline \multirow{9}{*}{$\begin{array}{l}\text { Measures } \\
\text { (in } \mathrm{mm} \text { ) }\end{array}$} & $Z y-Z y$ & $121.4( \pm 0.63)$ & $128.7( \pm 0.61)$ & $2.3 \times 10^{-14}$ \\
\hline & Zy-Ga-right & $90.2( \pm 0.55)$ & $95.5( \pm 0.45)$ & $2.1 \times 10^{-12}$ \\
\hline & Zy-Ga-left & $91.1( \pm 0.55)$ & $96.6( \pm 0.49)$ & $1.9 \times 10^{-12}$ \\
\hline & Zy-Ga (mean) & $90.6( \pm 0.53)$ & $96.1( \pm 0.45)$ & $2.5 \times 10^{-13}$ \\
\hline & Rhi-ANS & $29.5( \pm 0.37)$ & $33.2( \pm 0.31)$ & $1.2 \times 10^{-12}$ \\
\hline & Na Wid & $24.2( \pm 0.23)$ & $25.2( \pm 0.23)$ & $0.0025^{\star}$ \\
\hline & Na-ANS & $47.4( \pm 0.34)$ & $51.3( \pm 0.33)$ & $3.4 \times 10^{-14}$ \\
\hline & Ga-ANS & $57.9( \pm 0.41)$ & $61.6( \pm 0.4)$ & $1.1 \times 10^{-09}$ \\
\hline & $\mathrm{Ga}-\mathrm{Pr}$ & $71.6( \pm 0.67)$ & $76.7( \pm 0.57)$ & $2.6 \times 10^{-08}$ \\
\hline
\end{tabular}

*Statistically significant difference ( $p$-value<0.05).

${ }^{1}$ Race - Chi-squared; Measures - Unpaired Student's t test.

There was normal distribution ( $p>0.05)$, and variances were similar $(p>0.05)$ for all variables. Data analysis showed balance in the number of male and female samples (Chi-squared, $p=0.24)$, and race did not differ between sexes. However, all measures were significantly $(p<0.01)$ higher in males.

To observe if there was dependency between sexes with the other measures, a logistic regression (backward stepwise - Wald) was performed, considering males as "1" and females as "0" for calculation purposes, as Table 2 shows. At random, the chance to correctly predict the sex in the study sample would be $54.6 \%$.

The proposed model was significantly (Chi-squared=94.5; $p=6.4 \times 10^{-20}$, for cutoff value of 0.5$)$ better than chance to predict sex. Hosmer-Lemeshow test showed that the model was properly adjusted (Chi-square $=6.12, p=0.63$ ) to the data. In addition, the Nagelkerke $\mathrm{R}^{2}$ showed that the variables account for $52.6 \%$ of the variation found in sex. The logit was, therefore:

$$
\text { Sex }=-33.6+(0.15 \times \text { Zy-Zy })+(0.21 \times \text { Rhi-ANS })+(0.16 \times \text { Na-ANS }) \text {. }
$$

Values higher and lower than 0.5 (cutoff), respectively, would be regarded as "male" and "female." Table 3 shows the prediction considering this relationship. 
Table 2. Logistic regression mode/for sex determination.

\begin{tabular}{lccccc}
\hline Measures & Coefficient & Standard error & Wald & p-Value & $\begin{array}{c}\text { Standardized } \\
\text { coefficient }\end{array}$ \\
\hline Zy-Zy & 0.15 & 0.035 & 19.3 & $1.1 \times 10^{-05}$ & 1.17 \\
\hline Rhi-ANS & 0.21 & 0.074 & 8.4 & 0.0037 & 1.24 \\
\hline Na-ANS & 0.16 & 0.075 & 4.5 & 0.0332 & 1.17 \\
\hline Constant & -33.6 & 4.91 & 46.7 & $8.2 \times 10^{-12}$ & $2.7 \times 10^{-15}$ \\
\hline
\end{tabular}

Table 3 shows that the method results in $85.2 \%$ sensitivity, $76.2 \%$ specificity, and $81.1 \%$ accuracy, being, therefore, more effective in the prediction of sex than the mere random hit.

Table 3. Prediction of sex according to the logistic regression.

\begin{tabular}{ccccc}
\hline & & \multicolumn{2}{c}{ Prediction by formula } \\
\cline { 3 - 5 } & & Female & Male & Correct percentage \\
\hline Real sex & Female & 64 & 20 & 76.2 \\
\hline & Male & 15 & 86 & 85.2 \\
\hline & & Correct overall percentage & 81.1 \\
\hline
\end{tabular}

The regression also showed that the variables race $(p=0.64)$, Zy-Ga-right $(p=0.35)$, Zy-Ga-left ( $p=0.46)$, Zy-Ga-mean $(p=0.34)$, Na Wid $(p=0.40)$, Ga-ANS $(p=0.49)$, and $\mathrm{Ga}-\operatorname{Pr}(p=0.55)$ were not relevant for the model.

\section{Discussion}

It was verified that all linear measurements were dimorphic and it was possible to create a logistic regression model [logit: Sex $=-33.6+(0.15 \times \mathrm{Zi}-\mathrm{Zi})+(0.21 \times \mathrm{Ri}$-ENA $)+$ $(0.16 \times \mathrm{Na}-\mathrm{ENA})]$; to determine the sex obtaining $85.2 \%$ of sensitivity, $76.2 \%$ of specificity and $81.1 \%$ of accuracy.

Brazilian anthropometry only gained prominence in the nineteenth century, where Rodrigues began studies in Brazilians in order to prove the superiority of races (greater intellect, better strength and general health, besides anthropometrically determining the criminality of each individual ${ }^{16}$. It was intended to predict the possibility that some item of the phenotype (skin color, hair type, etc.) and anatomical aspects (broad and low head, etc.) could indicate whether or not an individual would be a criminal ${ }^{16}$.

These studies ${ }^{16}$ have proved imprecise and even prejudiced, and are not, in fact, studies that prove the Brazilian reality.

According to Penna ${ }^{16}$ (2002), this fact was studied by Roquete Pinto, who analyzed Brazilian mixed-race individuals (white individuals $\mathrm{x}$ black individuals $\mathrm{x}$ aborigens individuals), proved that they were intelligent, strong and healthy. 
This fact breaks the theory of the superiority of the "races", which considered the Brazilian " mixed-race individuals" to be "unfeasible" as part of a promising nation, recommending the whitening of the population, seeking the incorporation of attributes of the white individuals.

In Brazil, only after 1990, began anthropometric studies of real interest to identify a particular bone ${ }^{9}$. However, these studies occurred in a sparse way, with different methodology and the mathematical models obtained were in small, old samples, which could present a large margin of error when applied?

However, the incessant quest for quality has generated the need for methodological standardization. Such a feat became world-wide by Interpol ${ }^{17}$ (2014), who classified forensic anthropometry as a secondary method to be used in identification.

This situation, according to Jurda and Urbanová18 (2016), have demanded from the experts involved in the process an analysis of the need to improve existing mathematical models through the validation of developed models, as well as more complete qualitative evaluations and with greater reliability, and certainty about the achievement of the results (sex, age, race and height).

Anthropometric, quantitative (with linear and angular measurements) in teeth ${ }^{19}$, skulls ${ }^{20}$ and other bones of the human body ${ }^{21}$ have been stimulated, mainly because they generate discriminant functions and logistic regression, which are the result of scientific research that was duly evaluated by the editorial staff.

Most of the authors ${ }^{9}$ who studied the sexual dimorphism by logistic regression indicate that the skull alone allows the establishment of sex with approximately $77 \%$ or more of certainty and if the pelvis is also used it reaches $95 \%$.

However, it should be noted that in our country, similar to the European countries, there is a percentage of 15 to $20 \%$ of undifferentiated individuals (individuals with few differential characteristics) $)^{10}$.

Another problem frequently reported by anthropologists is that the of estimation sex by the qualitative method has generated the impression that these are more reliable than the quantitative method. It happens that such anthropologists forget that unintentionally, when analyzing anatomical aspects, they are actually measuring them, as an example is the pubic angle, which if open is female and if closed is male.

In this way, the performance of a qualitative evaluation can be in fact quantitative and in a certain plausible way of being measured, allowing the estimation of sex in a safe way. This study has already been carried out by photogrammetry using 3D laser scanner ${ }^{22}$.

In addition to choosing a reproducible methodology, it is also necessary to clearly specify how the sample to be evaluated will be composed, taking care to specify the age of the sample, its general race and sex. The sample studied is inserted into the bone biobank, composed of 320 complete bones, of which 184 are male and 136 are female. Of these, $58.75 \%$ are white individuals, $27.81 \%$ are mixed-race individuals, $13.12 \%$ black individuals and $0.32 \%(n=1)$ aborigens individuals. The cause of death is still further information. 
Another situation to be highlighted is the fact that it is necessary for the individual who comes to perform the measurements for anthropometric purposes to be initially calibrated (intra and inter-examiner calibration) and the assistance of an experienced anthropologist in order to avoid problems of errors in the location of the Anthropometric points to be measured.

The national literature ${ }^{9,23}$ and international ${ }^{10}$ are unanimous and affirm that the qualitative method when used alone is flawed, with only the exception for cases where even not measuring the structure analyzed, the evaluator can do it visually.

The result found in the present quantitative study is in agreement with the findings of other researchers ${ }^{24-27}$ in other countries and allows the estimation of sex in bones of missing individuals.

Another interesting situation is the use of computed tomography scans that allow internal structures to be measured with or without craniometric points ${ }^{28,29}$.

Computed tomography scanners must have minimum contrast, brightness and sharpness requirements and the software should allow visualization in axial, coronal and sagittal sections. In general, these software have a high cost and depend on a minimum knowledge of sectional anatomy. It should be noted that there are $3 \mathrm{~d}$ (three-dimensional) software that can measure even situations that are apparently immeasurable, such as rougher, more prominent, more prominent, so-called photogrammetry areas using 3D laser scanners, both of which are being developed By our group and soon the results will be released.

It was concluded that all measures performed are dimorphic and it was possible to create a logistic regression model to estimated the sex. It was concluded that the developed logistic regression model obtained $81.1 \%$ accuracy, which is therefore more effective in predicting sex than a simple visual qualitative test.

\section{Acknowledgements}

The authors are thankful to the CNPq for financial support.

\section{References}

1. Kanthem RK, Guttikonda VR, Yeluri S, Kumari G. Sex determination using maxillary sinus. J Forensic Dent Sci. 2015 May-Aug;7(2):163-7. doi: 10.4103/0975-1475.154595.

2. Francesquini Júnior L, Francesquini MA, De La Cruz BM, Pereira SD, Ambrosano GM, Barbosa CM, et al. Identification of sex using cranial base measurements. J Forensic Odontostomatol. 2007 Jun;25(1):7-11.

3. Bass WM. Recent developments in the identification of human skeletal material. Am J Phys Anthrop. 1969 May;30:459-62.

4. Bass WM, Driscoll PA. Summary of skeletal identification in Tennessee: 1971-1981, J Forensic Sci. 1983 Jun;28(1):159-68.

5. Isaza J, Díaz CA, Bedoya JF, Monsalve T, Botella MC. Assessment of sex from endocranial cavity using volume-rendered CT scans in a sample from Medellin, Colombia. Forensic Sci Int. 2014 Jan;234:186 e1-10. doi: 10.1016/j.forsciint.2013.10.023 
6. Krogman WM, Iscan MY. The human skeleton in Forensic Medicine. Ilinois: CC Thomas Publisher; 1986.

7. Rogers TL. Determining the sex of human, remains trough cranial morphology. J Forensic Sci. 2005 May;50(3):493-500.

8. Keen JA. A study of the differences between male and female skulls. Am J Phys Anthrop. 1950 Mar;8(1):65-79.

9. Daruge E, Daruge Júnior E, Francesquini Júnior L. [Treaty of Legal Dentistry and Deontology]. Rio de Janeiro: Guanabara Koogan; 2017. Portuguese.

10. Coma JMR. [Forensic Antropology]. Madrid: Ministerio da Justicia; 1999. Spanish.

11. Kharoshah MAA, Almadani O, Ghaleb SS, Zaki MK, Fattah YAA. Sexual Dimorphism of the Mandible in a Modern Egyptian Population. J Forensic Leg Med. 2010 May; 17(4):213-5. doi: 10.1016/j.jflm.2010.02.005.

12. Naikmasur VG, Shrivastava R, Mutalik S. Determination of Sex in South Indians and Immigrant Tibetans From Cephalometric Analysis and Discriminant Functions. Forensic Sci Int. 2010;197:122.e1-122.e6.

13. Oettle AC, Becker PJ, Villiers E, Steyn M. The Influence of Age, Sex, Population Group, and Dentition on the Mandibular Angle as Measured on a South African Sample. Am J Phys Anthropol. 2009 Aug;139(4):505-11. doi: 10.1002/ajpa.21009.

14. Rosa MA, Gonzáles E, Fregel R, Velasco J, Delgado T, Gonzáles AM, et al. Canary Islands Aborigin Sex Determination Based on Mandible Parameters Contrasted by Amelogenin Analysis. J Archaeol Sci. 2007 Sept;34(9):1515-22. doi: http://dx.doi.org/10.1016/j.jas.2006.11.008

15. Vanrell J. [Legal dentistry and forensic anthropology]. Rio de Janeiro: Guanabara Koogan; 2009. Portuguese.

16. Penna, SDJ, organizator. [Homo brasilis: Genetic, Linguistic, Historical and Socioanthropological Aspects of the Brazilian People's Formation]. Ribeirão Preto: FUNPEC; 2002. 191 p. Portuguese.

17. Interpol - Disaster Victim identification guide - 2014 [accessed 2017 Feb 7]. Available from: https:// www.interpol.int/INTERPOL-expertise/Forensics/DVI.

18. Jurda M, Urbanová P. Sex and ancestry assessment of Brazilian crania using semi-automatic mesh processing tools. Leg Med (Tokyo). 2016 Nov;23:34-43. doi: 10.1016/j.legalmed.2016.09.004.

19. Iqbal R, Zhang S, Mi C. Reability of mandibular canine and mandibular canine index in sex determination: a study using Uwghur population. J Forensic Leg Med. 2015 Jul;33:9-13. doi: 10.1016/j.jflm.2015.03.007.

20. Garvin HM, Sholts SB, Mosca LA. Sexual dimosphism in human cranial trait scores: effects of population, age, and body size. Am J Phys Anthropol. 2014 Jun;154(2):259-69. doi: 10.1002/ajpa.22502.

21. Dabbs GR, Moore-Jansen PH. A method for estimating sex using metric analysis of the scapula. J Forensic Sci. 2010 Jan;55(1):149-52. doi: 10.1111/j.1556-4029.2009.01232.x.

22. Urbanova P, Ross $A H$, Jurda M, Nogueira M. Testing the reliability of software tools in sex and ancestry estimation in a multi-ancestral Brazilian Sample. Leg Med (Tokyo). 2014 Sep;16(5):264-73. doi: 10.1016/j.legalmed.2014.06.002.

23. Silva M. [Compendium of Legal Dentistry]. São Paulo: Medsi; 1997. Portuguese.

24. Asghar A, Dixit A, Rani M. Morphometric Study of Nasal Bone and Piriform Aperture in Human Dry Skull of Indian Origin. J Clin Diagn Res. 2016 Jan;10(1):AC05-7. doi: 10.7860/JCDR/2016/15677.7148. 
25. Mahakkanukrauh P, Sinthubua A, Prasitwattanaseree S, Ruengdit S, Singsuwan P, Praneatpolgrang S, et al. Craniometric study for sex determination in a Thai population. Anat Cell Biol. 2015 Dec;48(4):275-83. doi: 10.5115/acb.2015.48.4.275.

26. Zaki ME, Soliman MA, El-Bassyouni HT. A cephalometric study of skulls from the Bahriyah oasis. J Forensic Dent Sci. 2012 Jul;4(2):88-92. doi:10.4103/0975-1475.109895.

27. Moreddu E, Puymerail L, Michel J, Achache M, DessI P, Adalian P. Morphometric measurements and sexual dimorphism of the piriform aperture in adults. Surg Radiol Anat. 2013 Dec;35(10):917-24. doi: 10.1007/s00276-013-1116-2.

28. Mana MD, Adalian P, Lynnerup N. Lateral angle and cranial base sexual dimorphism: a morphometric evaluation using computerised tomography scans of a modern documented autopsy population from Denmark. Anthropol Anz. 2016;73(2). doi: 10.1127/anthranz/2016/0424.

29. Tambawala SS, Karjodkar FR, Sansare K, Prakash N, Dora AC. Sexual dimorphism of foramen Magnum using cone beam computed tomography. J Forensic Leg Med. 2016 Nov;44:29-34. doi: 10.1016/j.jflm.2016.08.005. 